\title{
Inhaled corticosteroids should not be prescribed to all chronic obstructive pulmonary disease patients
}

\author{
Jean Bourbeau MD MSc FRCPC ${ }^{1, *}$, Andrew Mclvor MD MSc FRCPC FRCPE
}

\begin{abstract}
$\mathrm{C}$ Torticosteroids are one of many therapeutic modalities that

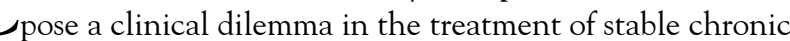
obstructive pulmonary disease (COPD). Years ago, the rationale for using corticosteroids in COPD was in part due to the unquestionable benefit in the treatment of asthma. As physicians, we have tended to transfer proven therapies from asthma to COPD. The hope has always been that inhaled corticosteroids will exert a similar effect in COPD patients as in asthma patients by suppressing inflammation reactions. The question of efficacy is of great importance, because long term use of corticosteroids, especially systemic or even high doses of inhaled corticosteroids, can potentially cause systemic adverse effects (1). As well, the cost associated with prescribing inhaled corticosteroids is far from negligible.
\end{abstract}

\section{SHORT TERM CLINICAL STUDIES}

Early studies have suggested that there are no benefits of short term inhaled corticosteroids (2-8). However, many of these studies had a limited sample size. In the occasional studies in which a benefit was shown $(9-11)$, patients were poorly defined (9) or the study included asthma patients (10). Outcomes were also limited to the measurement of forced expiratory volume in $1 \mathrm{~s}\left(\mathrm{FEV}_{1}\right)$ with questionable clinical relevance.

\section{LONG TERM CLINICAL STUDIES}

Recently, four long term studies - the European Study on Chronic Obstructive Pulmonary Disease (EUROSCOP) (12), the Copenhagen City Heart Study (13), the Inhaled Steroids in Obstructive Lung Disease in Europe (ISOLDE) study (14) and the Lung Health Study II (15) - provided evidence that inhaled corticosteroids do not slow the decline in lung function that occurs in patients with COPD. The hope has always been that inhaled corticosteroids will exert a similar effect in COPD patients as in asthma patients by suppressing inflammation reactions. However, the uncertainty of benefits of inhaled corticosteroids in suppressing airway inflammation in COPD patients (16-19) contrasts with the well-documented and consistent benefits in patients with asthma.

A reduction in the frequency of exacerbations was demonstrated in the ISOLDE study (14), but not in the
EUROSCOP (12) and Copenhagen City Heart Study (13), in which patients had mild disease. In the ISOLDE study, the effect on the annual exacerbation rate could not be demonstrated in patients with an $\mathrm{FEV}_{1}$ greater than $1.5 \mathrm{~L}$. More recently, a meta-analysis (20) was also able to confirm a beneficial effect of inhaled corticosteroids in reducing COPD exacerbations. The test for heterogeneity was significant, indicating that the effects of corticosteroids on exacerbations varied among the studies. The beneficial effect on exacerbations was driven largely by the ISOLDE study (14), in which the use of inhaled corticosteroids (fluticasone $1000 \mu \mathrm{g}$ /day or beclomethasone equivalent $2000 \mu \mathrm{g} /$ day) led to a $30 \%$ reduction in exacerbations.

\section{EPIDEMIOLOGICAL STUDIES}

A recent study by Sin and Tu (21) using health care databases showed that among subjects 65 years of age or older who were discharged from hospital with a diagnosis of COPD, any prescription of inhaled corticosteroids dispensed within 90 days of hospital discharge was associated with a marked reduction in all-cause mortality. Similarly, Soriano et al (22), using the same study methodology, showed a marked reduction in allcause mortality with increased doses of fluticasone in combination with salmeterol or fluticasone alone. These findings from pharmacoepidemiology studies using similar research methodologies should be interpreted cautiously and cannot be considered definitive. Although pharmacoepidemiology studies are useful complements to randomized clinical trials, randomized clinical trials have not been able to show a reduction in mortality for those patients treated with inhaled corticosteroids. As part of a recent meta-analysis (20), five of nine studies that looked at mortality as a secondary outcome found that there was no reduction in all-cause mortality in patients taking inhaled corticosteroids compared with those not taking inhaled corticosteroids.

\section{BENEFIT TO RISK RATIOS}

It remains uncertain whether using high dose inhaled corticosteroids for long periods of time is associated with a favourable risk-benefit ratio. Local adverse effects have been well docu-

\footnotetext{
${ }^{1}$ Montreal Chest Institute of the Royal Victoria Hospital, McGill University Health Centre, Montreal, Quebec; ${ }^{2}$ Halifax Infirmary Site, Dalhousie University, Halifax, Nova Scotia

*Dr Jean Bourbeau is the recipient of a research scholarship, Fonds de la Recherche en Santé du Québec, Montreal, Quebec

Correspondence: Dr Jean Bourbeau, Respiratory Epidemiology Unit, Lady Meredith House, 1110 Pine Avenue West, Montreal, Quebec

H3A 1A3. Telephone 514-398-6977 or 514-398-2718, fax 514-398-8981, e-mail jean.bourbeau@mcgill.ca
} 
mented. In randomized clinical trials, increased skin bruising has been shown in COPD patients treated with inhaled corticosteroids, while effects on bone mineral density was variable (20). Because of a relatively short duration of follow-up, no differences in the rates of cataracts or fractures could be demonstrated in these clinical trials $(12,15)$.

The results of a recent systematic review and meta-analysis by Lipworth (1) have shown that marked adrenal suppression occurred with high doses of inhaled corticosteroids (beclomethasone equivalent higher than $1500 \mu \mathrm{g} /$ day) in patients with asthma, although there is a considerable degree of interindividual susceptibility. Inhaled corticosteroids in doses higher than $1500 \mu \mathrm{g} /$ day of beclomethasone equivalent can be associated with a significant reduction in bone density, although the risk for osteoporosis can be obviated by postmenopausal estrogen replacement therapy. Furthermore, long term, high dose inhaled corticosteroid exposure can increase the risk of posterior subcapsular cataracts, and, to a much lesser degree, ocular hypertension and glaucoma. Because COPD patients are generally older than asthmatic patients, the prolonged use of high dose inhaled corticosteroids may pose a greater risk in this group.

\section{REFERENCES}

1. Lipworth BJ. Systemic adverse effects of inhaled corticosteroid therapy. A systemic review and meta-analysis. Arch Intern Med 1999;159:941.

2. Hall TG, Kasik JE, Bedell GN, Schaiff RA. The efficacy of inhaled beclomethasone in chronic obstructive airway disease. Pharmacotherapy 1989;9:232-9.

3. Engel T, Heinig JH, Madsen O, Hansen M, Weeke ER. A trial of inhaled budesonide on airway responsiveness in smokers with chronic bronchitis. Eur Respir J 1989;2:935-9.

4. Auffarth B, Postma DS, de Monchy JG, van der Mark TW, Boorsma M, Koeter GH. Effects of inhaled budesonide on spirometric values, reversibility, airway responsiveness, and cough threshold in smokers with chronic obstructive lung disease. Thorax 1991;46:372-7.

5. Wempe JB, Postma DS, Breederveld N, Kort E, van der Mark TW, Koeter GH. Effects of corticosteroids on bronchodilator action in chronic obstructive lung disease. Thorax 1992:616-21.

6. Renkema TEJ, Schouten JP, Koeter GH, Postma DS. Effects of long-term treatment with corticosteroids in COPD. Chest 1996;109:1156-62.

7. Llewellyn-Jones CG, Harris TAJ, Stockley RA. Effect of fluticasone propionate on sputum of patients with chronic bronchitis and emphysema. Am J Respir Crit Care Med 1996;153:616-21.

8. Boothman-Burrell D, Delany SG, Flannery EM, Hancox RJ, Taylor DR. The efficacy of inhaled corticosteroids in the management of non-asthmatic chronic airflow obstruction. N Z Med J 1997;110:370-3.

9. Weir DC, Gove RI, Robertson AS, Burge PS. Corticosteroid trials in non-asthmatic chronic airflow obstruction: a comparison of oral prednisolone and inhaled beclomethasone dipropionate. Thorax 1990;45:112-7.

10. Kerstjens HA, Brand PL, Quanjer PH, et al. Variability of bronchodilator response and effects of inhaled corticosteroid treatment in obstructive airways disease. Dutch CNSLD Study Group. Thorax 1993;48:722-9.

11. Weiner P, Weiner M, Azgad Y, Zamir D. Inhaled budesonide therapy for patients with stable COPD. Chest 1995;8:1568-71.

12. Pauwels RA, Lofdahi C-G, Laitinen LA, et al. Long-term treatment with inhaled budesonide in persons with mild chronic obstructive

\section{CONCLUSIONS}

To our great dissatisfaction, we have to recognize that only smoking cessation can slow the rate of change of lung function, which is often thought to represent the course of COPD. Of the pharmacological therapies, bronchodilators are the most important agents to relieve symptoms in COPD patients.

Numerous long term, randomized clinical trials have shown that corticosteroids show no benefit in slowing the annual decline in lung function characteristic of COPD. When trying to interpret the data of these long term studies, the relevance of any potential clinical benefits should be balanced with the patient's disease severity and the risk for systemic adverse effects. In mild disease, no beneficial effect has been demonstrated. In contrast to asthma, inhaled corticosteroids should not be used as first-line medication. In moderate to severe disease, inhaled corticosteroids may reduce the exacerbation rate, although this demands the use of high dose inhaled corticosteroids, consequently increasing the risk of systemic adverse effects. Inhaled corticosteroids should not be prescribed to all COPD patients. The potential for a limited clinical benefit contrasts sharply with the high likelihood of adverse effects when inhaled corticosteroids are used at high doses for prolonged periods in elderly patients.

pulmonary disease who continue smoking. European Respiratory Society Study on Chronic Obstructive Pulmonary Disease. N Engl J Med 1999;340:1948-53.

13. Vestbo J, Sorensen T, Lange P, Brix A, Torre P, Viskum K. Long-term effect of inhaled budesonide in mild and moderate chronic obstructive pulmonary disease: a randomised controlled trial. Lancet 1999;353:1819-23.

14. Burge PS, Caverley PM, Jones PW, Spencer S, Andersen JA, Maslen TK. Randomised, double blind, placebo controlled study of fluticasone propitionate in patients with moderate to severe chronic obstructive pulmonary disease. The ISOLDE trial. BMJ 2000;320:1297-303.

15. Effect of inhaled triamcinolone on the decline in pulmonary function in chronic obstructive pulmonary disease. N Engl J Med 2000;343:1902-9.

16. Culpitt SV, Maziak W, Loukidis S, Nightingale JA, Matthews JL, Barnes PJ. Effects of high doses of inhaled steroids on cells, cytokines, and proteases in induced sputum in chronic obstructive pulmonary disease. Am J Respir Crit Care Med 1999; 160:1635-9.

17. Keatings VM, Jatakanon A, Worsdell YM, Barnes PJ. Effects of inhaled and oral glucocorticoids on inflammatory indices in asthma and COPD. Am J Respir Crit Care Med 1997;155:542-8.

18. Confalonieri M, Mainardi E, Della Porta R, et al. Inhaled corticosteroids reduce neutrophilic bronchial inflammation in patients with chronic obstructive pulmonary disease. Thorax 1998;53:583-5.

19. Yildiz F, Kaur AC, Ilgazli A, et al. Inhaled corticosteroids may reduce neutrophilic inflammation in patients with stable chronic obstructive pulmonary disease. Respiration 2000;67:71-6.

20. Alsaeedi A, Sin DD, McAlister FA. The effects of inhaled corticosteroids in chronic obstructive pulmonary disease: A systematic review of randomized placebo-controlled trials. Am J Med 2002;113:59-65.

21. Sin DD, Tu JV. Inhaled corticosteroids and the risk of mortality and readmission in elderly patients with chronic obstructive pulmonary disease. Am J Respir Crit Care Med 2001;164:580-4.

22. Soriano JB, Vestbo J, Pride NB, Kiri V, Maden C, Maier WC. Survival in COPD patients after regular use of fluticasone propionate and salmeterol in general practice. Eur Respir J 2002;20:819-25. 


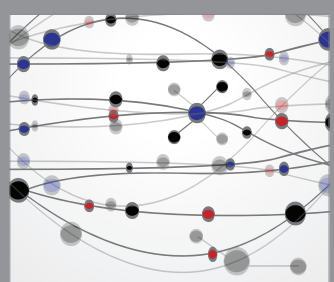

The Scientific World Journal
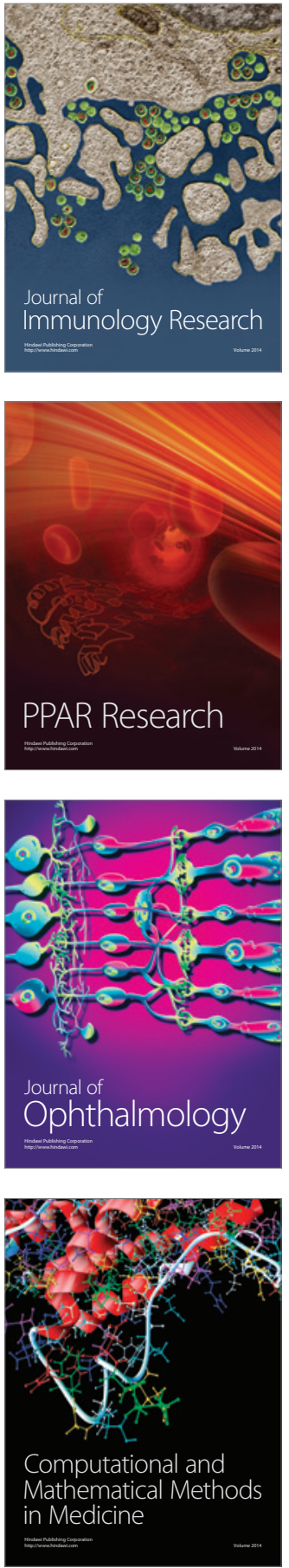

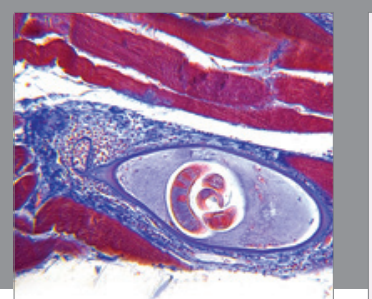

Gastroenterology Research and Practice

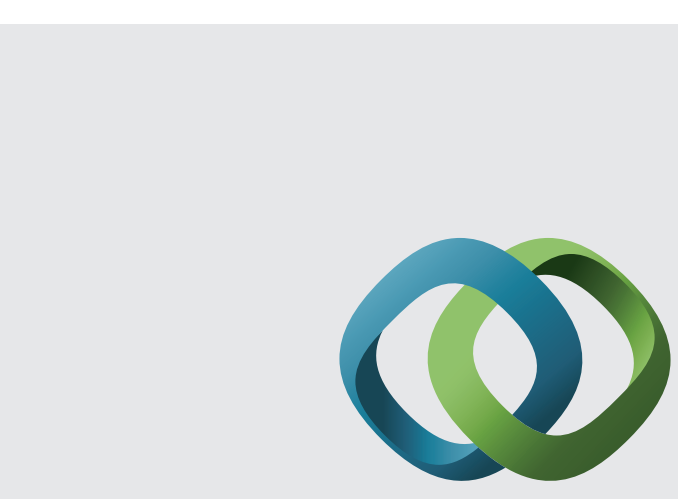

\section{Hindawi}

Submit your manuscripts at

http://www.hindawi.com
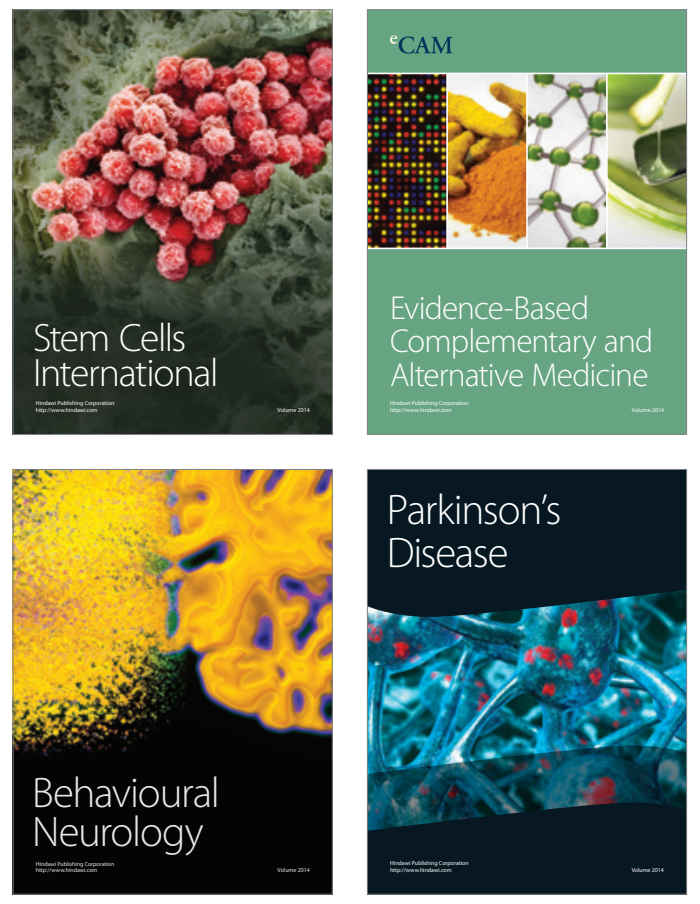
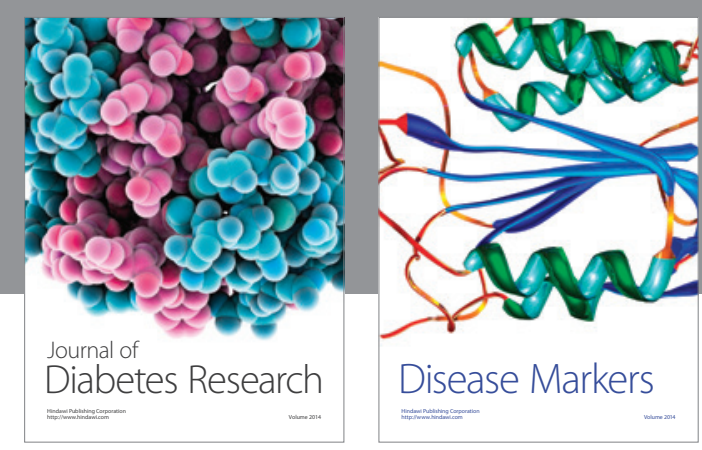

Disease Markers
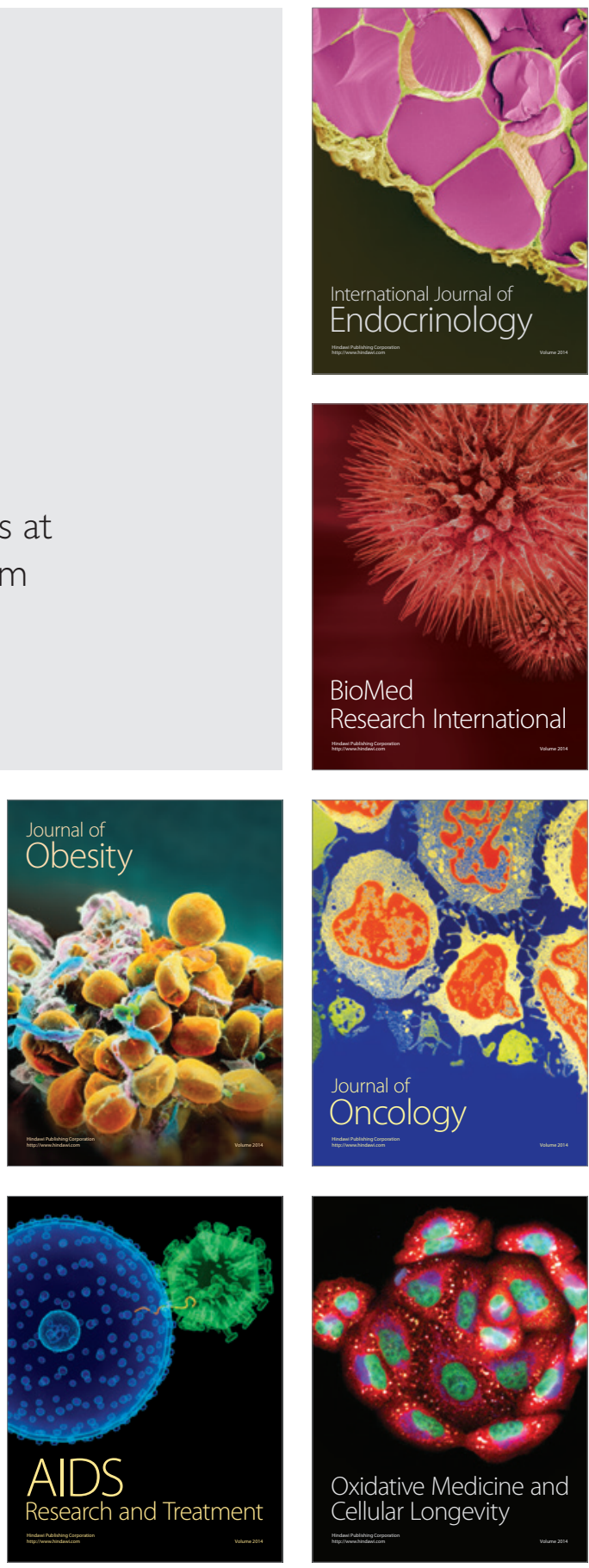